Rev. Col. Bras. Cir.

Vol. 33 - № 1: 1, Jan. / Fev. 2006

\title{
O COLÉGIO BRASILEIRO DE CIRURGIÕES E A CAPACITAÇÃO DO CIRURGIÃO
}

\section{THE BRAZILIAN COLLEGE OF SURGEONS AND THE EDUCATIONAL PROGRAMS FOR SURGEONS}

\section{TCBC José Reinan Ramos \\ Presidente do $C B C$}

É uma honra extraordinária poder servir ao Colégio Brasileiro de Cirurgiões como seu $32^{\circ}$ Presidente. Espero cumprir essa missão com sucesso, pois vou trabalhar com um Diretório altamente qualificado e juntos pretendemos modernizar o CBC, com seriedade e planejamento.

É preciso unir o cirurgião brasileiro em torno do nosso Colégio e restaurar a afinidade e o carisma do cirurgião com a Sociedade. É fundamental que retomemos com ética e esclarecimento esta supremacia, que foi em parte distanciada pela tecnologia contemporânea sem regulamentação. O Colégio Brasileiro de Cirurgiões recomenda qualidade máxima do exercício profissional e menor compartimentação especializada do saber e do fazer para melhor proteção e defesa dos pacientes.

O Colégio Brasileiro de Cirurgiões vem nos últimos anos contribuindo cada vez mais para a melhoria da saúde da população brasileira, através de várias ações que convergem para o aperfeiçoamento do cirurgião. O cirurgião melhor capacitado e titulado é garantia de assistência de qualidade à população.

Várias ações serão desenvolvidas para aperfeiçoar as atividades científicas e de Educação Continuada, entre elas:
1. A indexação da Revista do Colégio Brasileiro de Cirurgiões no PUBMED;

2. O melhoramento das ferramentas de comunicação para aperfeiçoamento dos nossos membros e para não só melhorar a qualidade da informação como também incentivar a qualificação dos cirurgiões;

3. A viabilização de programas pela Internet para discutir a Cirurgia em vários contextos e facilitar, a agora, obrigatória certificação de atualização profissional;

4. Articular parcerias tecno-científicas com as universidades e seus departamentos de cirurgia, procurando estimular a reciclagem dos cirurgiões;

5. Promover o Programa de Atualização em Cirurgia (PROACI) em convênio com a Artmed/Panamericana Editora.

Com essas e outras ações e a participação de todos os membros, vamos aumentar a representatividade do Colégio Brasileiro de Cirurgiões em todo o país e melhorar a qualificação do Cirurgião.

Seja Membro do CBC e valorize ainda mais o Cirurgião Brasileiro. 